\title{
EXPERIMENTAL PRODUCTION OF FORWARD DISLOCATION IN THE HUMAN CERVICAL SPINE
}

\author{
ROBERT J. BAUZE, GORDON M. ARDRAN
}

\author{
From the Nuffield Institute for Medical Research, Oxford, the Nuffield Department of Orthopaedic Surgery, \\ University of Oxford, and the Spinal Injuries Unit, Royal Adelaide Hospital
}

\begin{abstract}
Entire human cadaveric cervical spines with the basiocciput were subjected to load in a compression apparatus to simulate the clinical situation of forward dislocation. The movements were recorded by lateral cineradiography. Vertical load was measured by a potentiometric transmitter synchronised with each frame of the cineradiograph. The lower part of the spine was flexed and fixed, and the upper extended and free to move forward. Vertical compression then produced bilateral dislocation of the facets without fracture. If lateral tilt or axial rotation occurred as well, a unilateral dislocation was produced. The maximum vertical load was only 145 kilograms, and coincided with the rupture of the posterior ligament and capsule and the stripping of the anterior longitudinal ligament, but this occurred before dislocation. The low vertical load indicates a peculiar vulnerability of the cervical spine in this position and correlates well with the minor trauma often seen in association with forward dislocation.
\end{abstract}

Forward dislocation of the cervical spine is well demonstrated by a typical case history. A man aged twenty was standing in a river in two feet of water. He dived in, hit his head, and was immediately tetraplegic. He did not lose consciousness, and remembers being dragged out by his friends. He had a small bruise on the top of his head. A lateral radiograph of his cervical spine is shown in Figure 1.

The mechanism of this injury is not established. Some clinicians have suggested that hyperflexion alone causes bilateral dislocation of the facets, but when associated with lateral bending or rotation it causes unilateral dislocation (Norton 1962; Braakman and Vinken 1967). Taylor and Blackwood (1948) suggested that extension was the cause. Few experiments have been performed to study the injury. Roaf (1960), using cadaveric spines, was unable to produce dislocation by hyperflexion alone. He concluded that hyperflexion must cause a fracture of the vertebral body, as the force required to rupture the posterior ligaments was above that which would cause anterior wedge compression fracture. He found that subluxation could be "easily produced" by axial rotation and concluded that cervical dislocation was due to rotation forces. If there was associated compression, then fracture-dislocation occurred. Beatson (1963) performed an experiment on a cadaver to demonstrate the integrity of the spinous and capsular ligaments in dislocated cervical spines, but his method of production of the injury was not described.
The study reported here simulates the clinical situation. This has only been possible by avoiding certain constraints of engineering which if applied would make

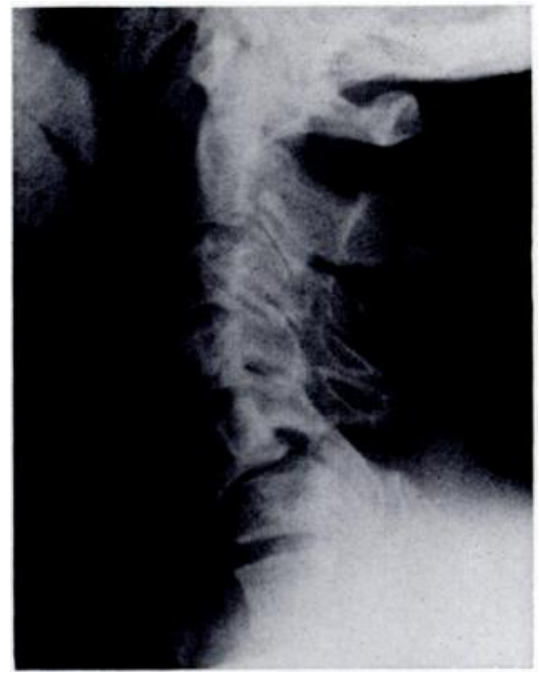

Fig. 1

Lateral radiograph of bilateral dislocation of the C5-6 facets. (Case report in text.)

the condition unnatural. The intention in performing the experiment was to produce the injury, record the vertical load, analyse the movement and forces involved, and to compare it with the clinical situation.

R. J. Bauze, M.B., B.S., F.R.A.C.S., Senior Visiting Surgeon, Department of Orthopaedic Surgery and Spinal Injuries Unit, Royal Adelaide Hospital, Adelaide, South Australia, 5000

G. M. Ardran, M.D., F.F.R., Director of Radiology, Nuffield Institute for Medical Research, Radcliffe Observatory, Woodstock Road, Oxford, England.

Requests for reprints should be sent to Mr R. J. Bauze, 183 Tynte Street, North Adelaide, South Australia, Australia 5006. 


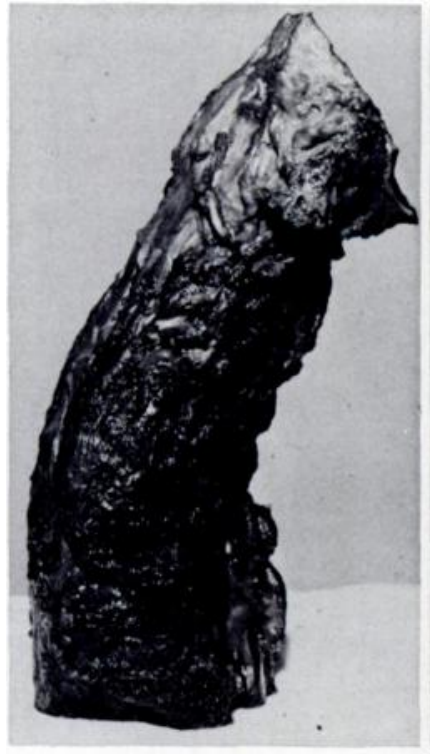

Fig. 2

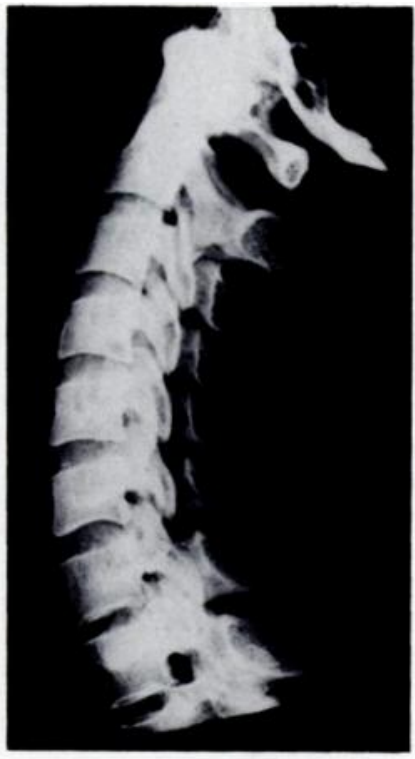

Fig. 3
Figure 2-Specimen of cadaveric cervical spine as used in the experiment. Figure 3-Radiograph of the same specimen.

\section{MATERIAL AND METHODS}

Specimen. Fourteen specimens were obtained at necropsy from patients aged from thirty-one to seventy-two years. Each specimen consisted of the basiocciput and the attached spine and paraspinal muscles down to the fifth thoracic vertebra (Fig. 2), and all ligaments were preserved intact. The specimens were stored at -20 degrees Celsius. Immediately before the experiment each specimen was thawed in warm water for about one hour. It was then trimmed so that it consisted of a ring of basiocciput that was flat superiorly, the

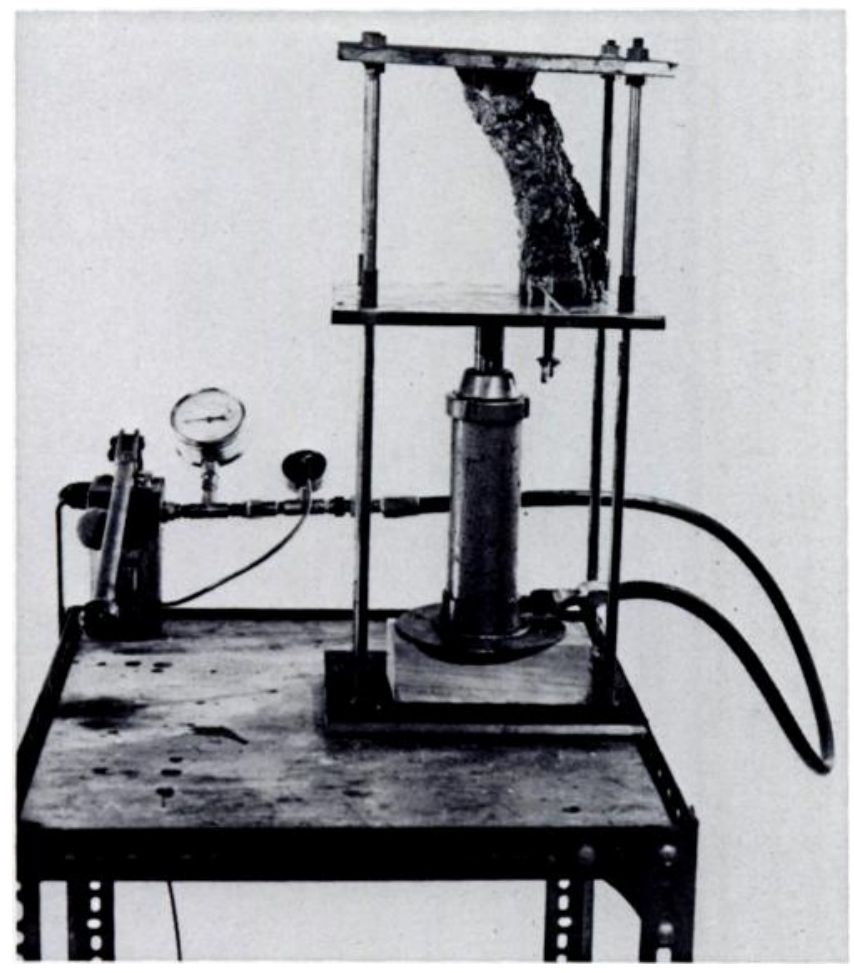

Fig. 4

Apparatus used to apply and record the vertical load on the specimen, shown with cervical spine in position. (Description in text.) complete cervical spine, and usually the first one and a half thoracic vertebrae (Fig. 3).

Loading apparatus. The basic concept of this was taken from Selecki (1970). Fundamental modifications, however, were made in the apparatus to produce a more physiological experiment, and to produce a dislocation without fracture (Fig. 4). It consisted of three flat plates of steel assembled so that the upper and lower plates were fixed to four vertical steel rods. The middle plate could travel smoothly up the rods. Upward movement of the middle plate was achieved by a manually operated hydraulic jack interposed between the middle and lower plates. A steel spindle passed through the middle plate and up the spinal canal of the specimen, and was adjustable to select a level for dislocation. An acrylic sleeve fitted the spindle and was individually made for each specimen to give a snug fit in the lower spinal canal. Four lugs were attached to the middle plate as guides and fixation for a Steinmann pin which was passed through the lowest vertebral body and prevented its rotation.

Recording apparatus. Lateral cineradiographs were taken of the specimen during increasing load at four frames per second on 35 millimetre film. Vertical load was measured by a visual pressure gauge and more accurately by a potentiometric transmitter incorporated in the hydraulic line. Both these instruments were calibrated to load by using weights placed on the middle plate of the loading apparatus. The output of the transmitter was fed into an Elema Mingograph direct ink writing apparatus which was linked to the cineradiography machine so that the written record showed the vertical load on the specimen synchronised with pulses indicating individual frames of the cineradiograph.

\section{EXPERIMENT}

The specimen was fitted on the acrylic sleeve and the metal spindle of the middle plate, and jammed in a flexed position between the middle and upper plates by applying pressure through the jack. The previously prepared flat surface of basiocciput lay flush against the smooth, lubricated under surface of the upper plate (Fig. 4). Further increase in pressure narrowed the gap between the middle and upper plates and increased the load on the specimen. The basiocciput slid forward, with extension of the atlanto-occipital joints and the upper cervical spine, and flexion of the midcervical region. The increasing vertical load thereby created a combination of vertical compression, flexion, and horizontal shear forces at the junction of fixed and mobile parts of the spine. Forward dislocation was the result. The experiment took from four to twelve seconds, the time being dependent on the speed of operation of the jack. Movements and loads were then analysed from the various recordings.

\section{Movement}

\section{RESULTS}

Figure 5 shows selected frames from one of the cineradiographs. The progress of dislocation is seen as a steady, smooth process. Initially there is increasing extension at the atlanto-occipital joints, and flexion at the level above the spindle. As the load increases and the plates approximate, the posterior ligaments rupture. Stripping of the anterior longitudinal ligament then occurs with the fifth cervical vertebra shearing forward on the sixth; the facets are subluxed but not yet dislocated. Dislocation occurs with the body of the fifth vertebra running down the front of the sixth, further stripping the anterior longitudinal ligament. When the specimen was removed from the rig it was tied with thread in extension to simulate contraction of extensor muscles. Figure 6 shows bilateral locked facets identical to the clinical picture. Figure 7 was taken after manipulative reduction when no lesion was apparent. 

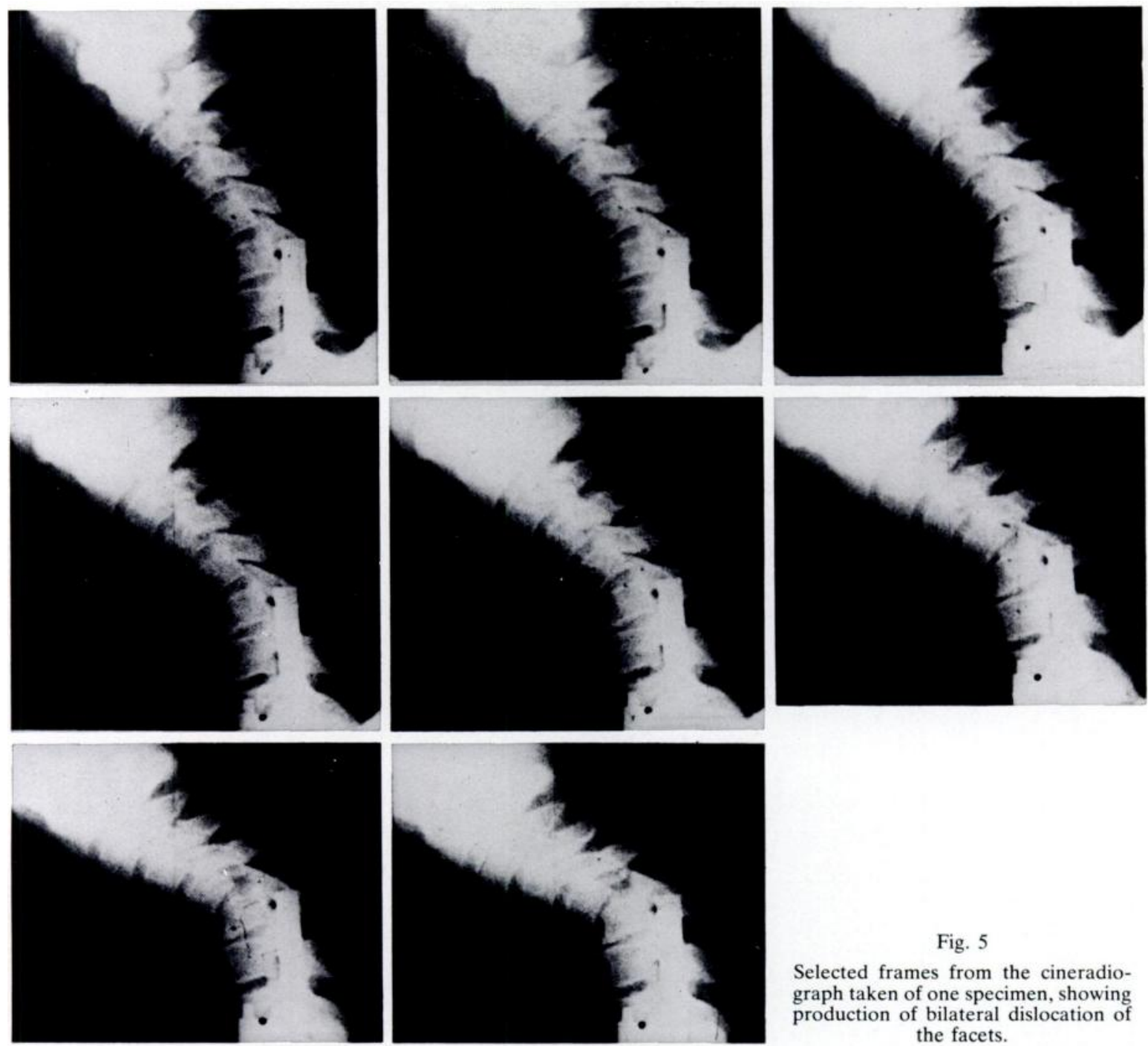

Fig. 5

Selected frames from the cineradiograph taken of one specimen, showing production of bilateral dislocation of the facets.

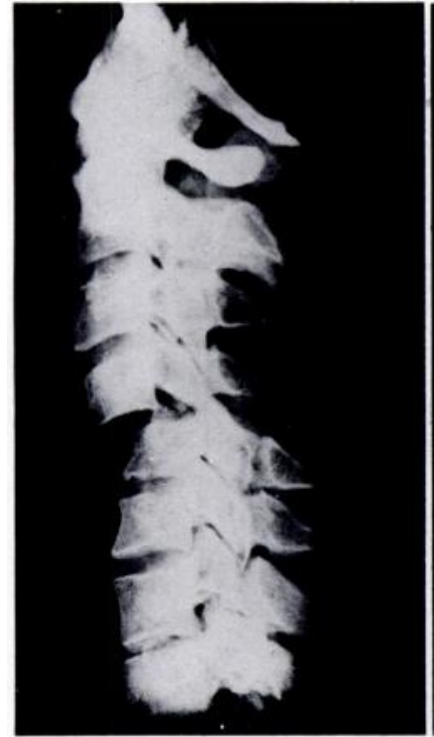

Fig. 6

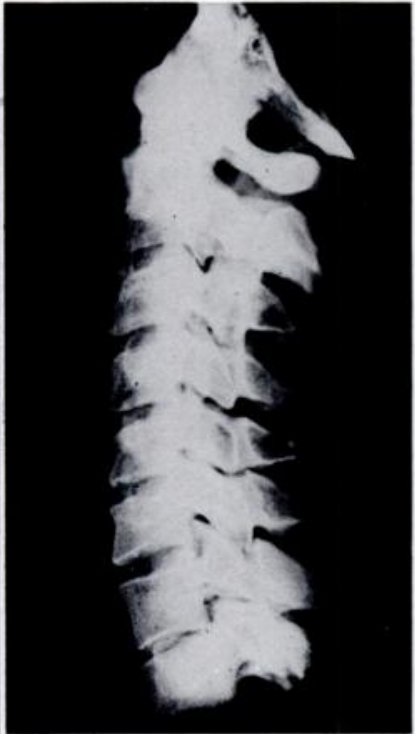

Fig. 7

After completion of the experiment, the specimen was extended. Figure 6-Bilateral dislocation of the facets. Figure 7-After reduction, showing no significant lesion.

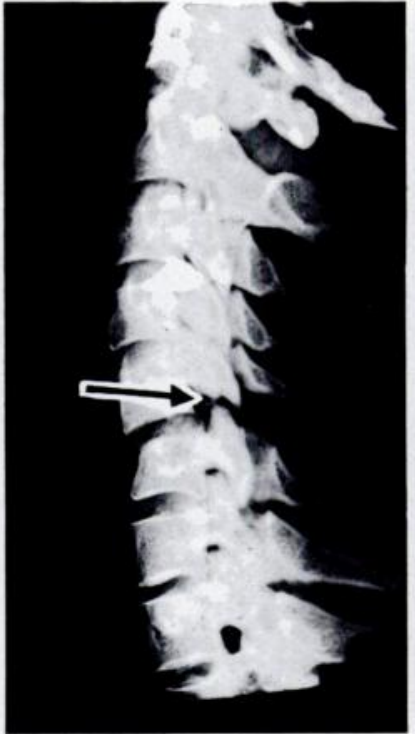

Fig. 8

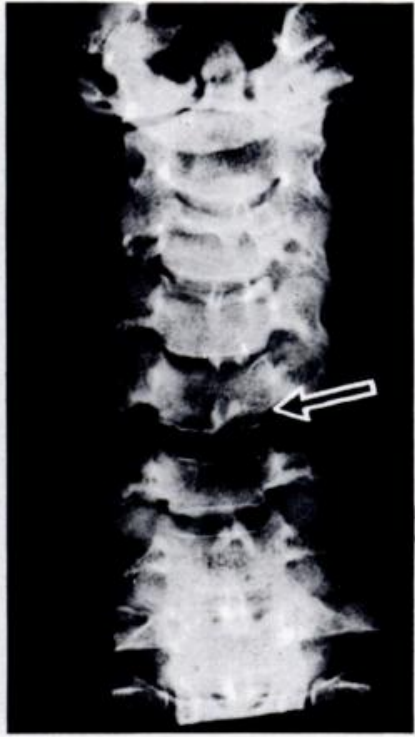

Fig. 9

A specimen which sustained a unilateral facet dislocation. Figure 8-One facet is indicated in front of its partner below, the other is subluxed. Figure 9-A fracture of the antero-inferior corner of the vertebral body on the contralateral side to the dislocated facet. 
Of the fourteen specimens, six dislocated as described above, without fracture of facet, body or lamina. One specimen dislocated, without fracture, at the level above fixation. Three dislocated at the level below fixation, by the spindle breaking through the lamina of the fixed vertebra, while the facets behaved as in the first six. Two specimens dislocated on one side

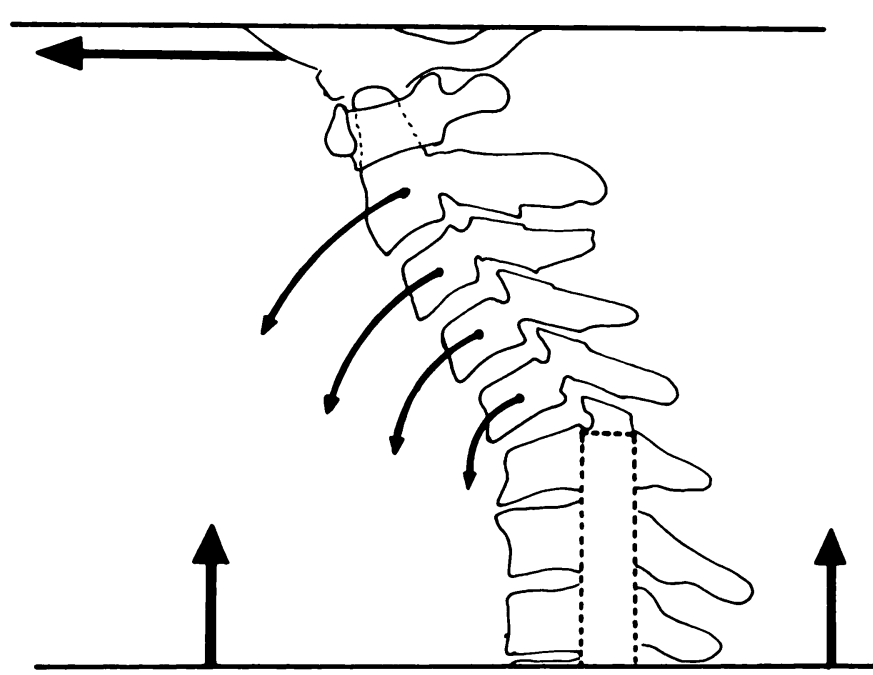

Fig. 10

A tracing of a specimen showing the principle directions of movement in the experiment.

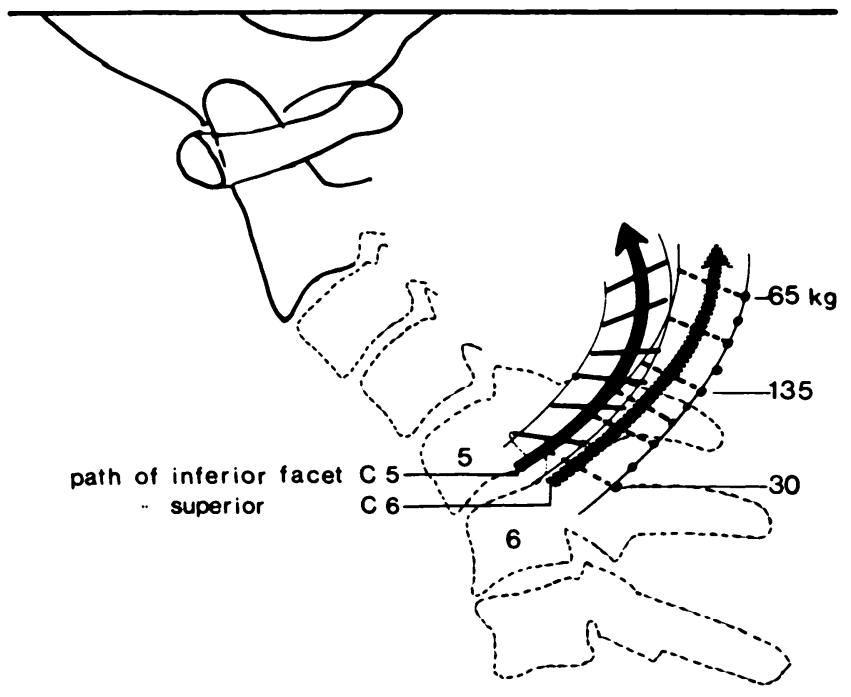

Fig.11

The paths taken by dislocating facets traced from cineradiograph frames, relative to a fixed basiocciput.

only. In both, control had been lost and considerable rotation and lateral flexion had occurred. One of them fractured at the opposite antero-inferior corner of the superior vertebral body (Figs. 8 and 9). In another specimen the basiocciput did not slide forward and a wedge compression fracture of the vertebral body occurred, similar to the lesion produced by Selecki (1970). The remaining specimen, from a small, osteoporotic and aged woman, sustained a shear fracture through the body and both facets.

Analysis of movement. In the experiment the lower levels of the spine were fixed anteroposteriorly but moved closer to the basiocciput in a longitudinal direction, while the basiocciput slid anteriorly away from the lower spine (Fig. 10). The relative movements are similar to those seen clinically where the basiocciput is stationary and the lower neck is moving relative to it. To demonstrate this, tracings were made of the adjoining facets in sequential frames of one of the cineradiographs and superimposed, making the basiocciput fixed. Figure 11 shows the paths of adjoining facets from the jamming position to dislocation. By turning the sketch upside down the similarity to a diving injury is seen. The head is fixed, the shoulders move in the direction of the momentum, causing increased flexion at the midcervical level and ultimate separation of the facets. As noted by Fielding (1957) and Lysell (1972), flexion and extension occur in the sagittal plane and are accompanied by shear; this movement is shown in Figure 12. In Figure 13 tracings of a cineradiograph show extension to dislocation. Forward dislocation is seen as a continuation of flexion.

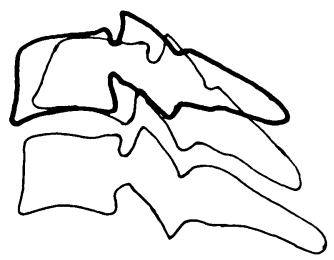

Fig. 12

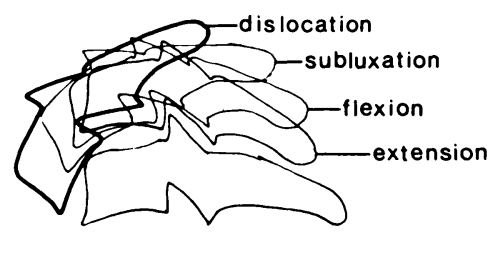

Fig. 13
Figure 12-Tracing taken of a normal spine at C5-6 moving from extension to flexion. Note the degree of shear involved, and the facets of $\mathrm{C5}$ riding up on those of C6. Figure 13-Tracings taken from a specimen showing dislocation as a steady progression from flexion.

\section{Load}

Vertical load recordings from the potentiometric transmitter and synchronised with the cineradiograph frames are shown for one specimen (Fig. 14). Three features are worth noting: the maximum load was 135 kilograms; it was reached before dislocation; and dislocation occurred with decreasing load. In other words, dislocation occurred and progressed at a vertical load lower than that which ruptured the ligaments preventing it.

Other specimens gave the same basic result. The highest vertical load recorded was 145 kilograms.

Analysis of load. The forces acting on the specimen were complicated but are simply shown in Figure 15. At the point of dislocation there was a major anterior shear component and a minor compression. The abnormal forces caused by the spindle can possibly be related clinically to fixation by muscles. Certainly the lower cervical spine normally moves less than the middle section. Because of the anterior shear component, fracture of the vertebral body does not occur. 

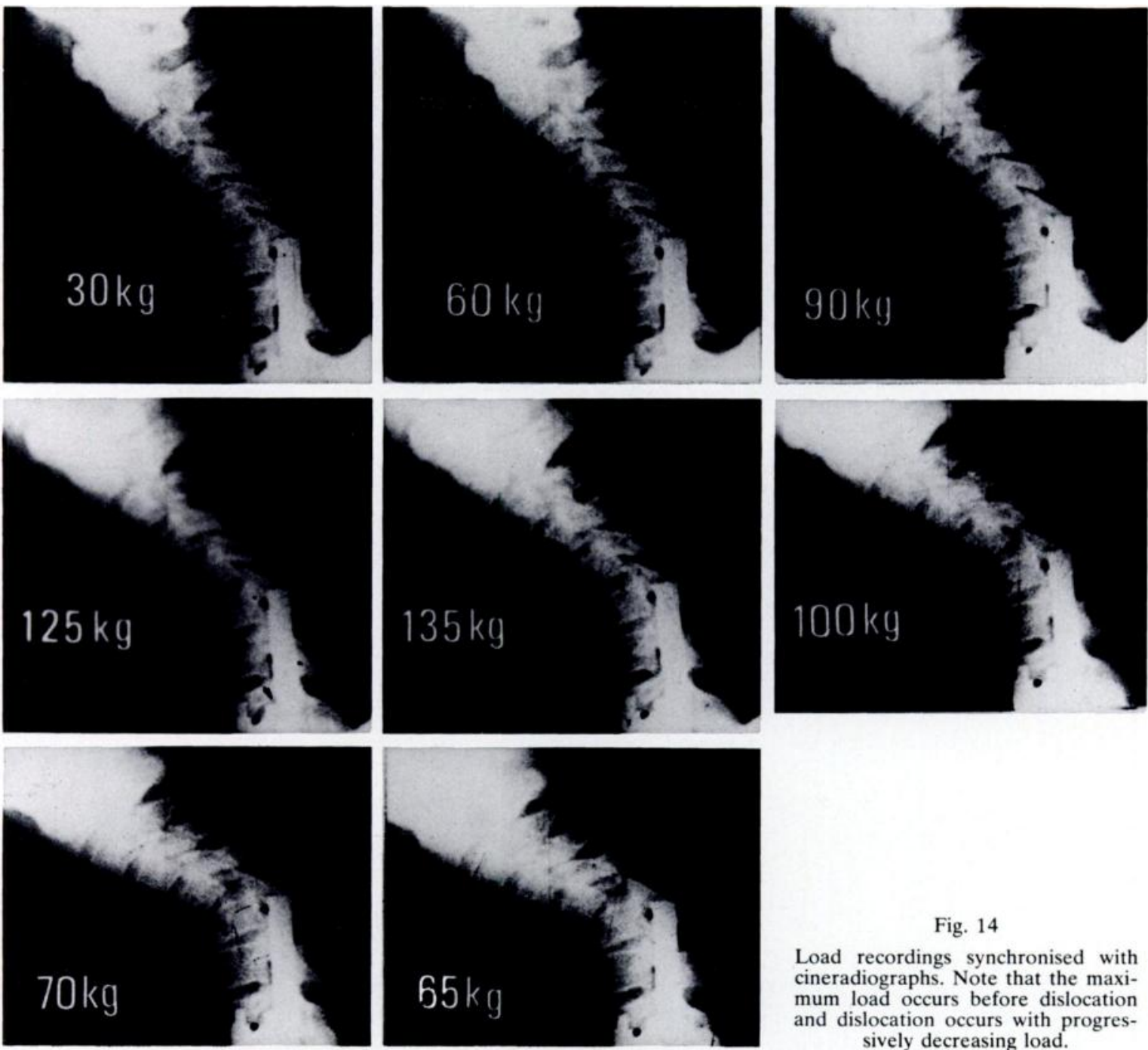

Fig. 14

Load recordings synchronised with cineradiographs. Note that the maximum load occurs before dislocation and dislocation occurs with progressively decreasing load.

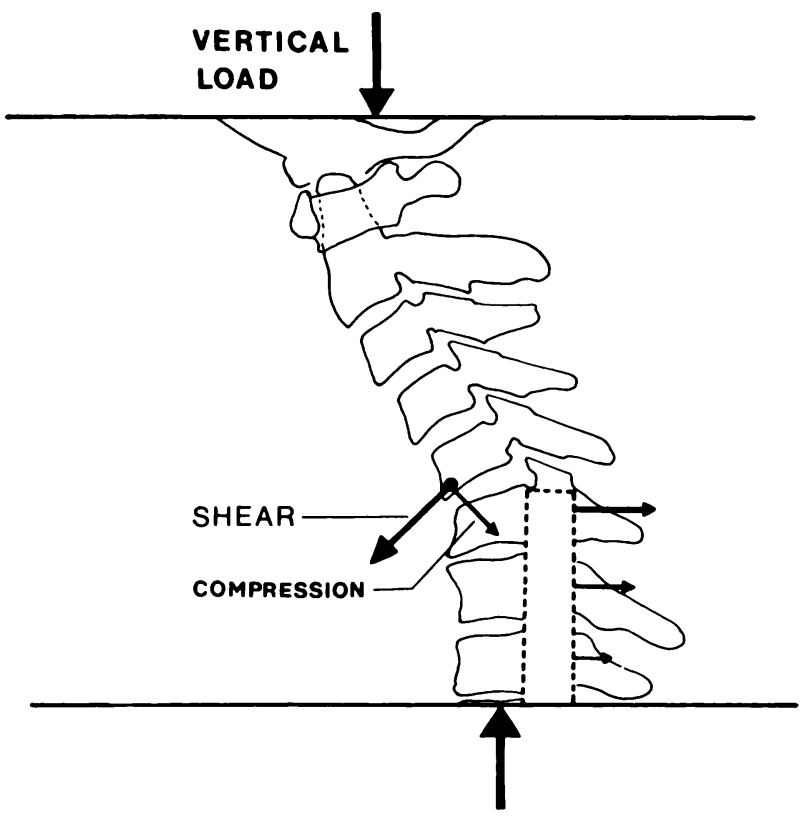

Fig. 15

The major forces acting on the specimen.

\section{DISCUSSION}

The type of injury suffered by a cervical spine depends on the attitude of the head and neck at time of impact, the point of impact, the direction and amount of force, and the continuing, changing positions and force experienced before it comes to rest. This experiment attempted to simulate such a naturally occurring event, and thus to produce a naturally occurring injury. Roaf subjected isolated spinal units (two vertebrae and a disc) to compression in flexion in an Instron testing machine and, as expected, caused an anterior crush fracture. This ignored the natural, changing axis of flexion with its element of shear which this experiment allowed to occur naturally.

The particular attitude of the specimen in the apparatus was that of upper cervical extension and midcervical flexion associated with lower cervical fixation. Such an attitude was first described by Cornish (1968) as the "ducking" position. Figure 16 shows this position in a normal person. It is interesting that this is the position usually adopted by an inexperienced diver. 

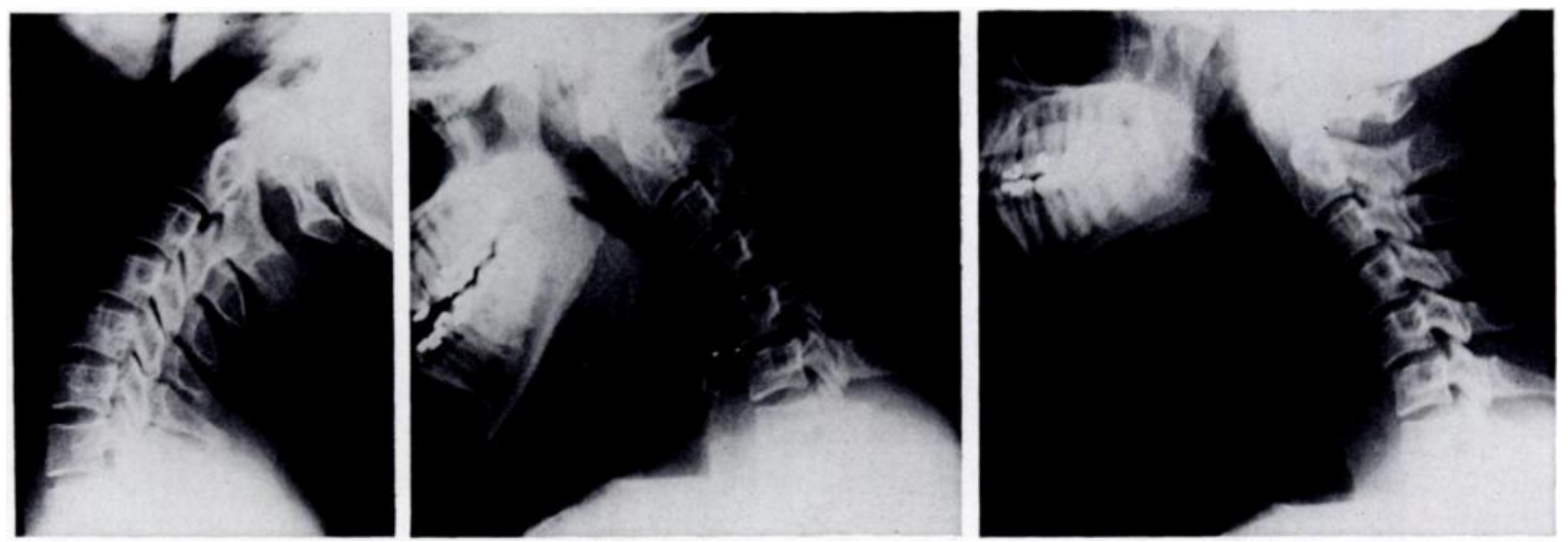

Fig. 16

Radiographs showing a normal spine in extension, in flexion and in the "ducking" position with extension at atlanto-occipital and upper cervical joints and flexion at midcervical and lower cervical spine. Note that with further flexion and vertical compression the chin could travel down the front of the chest and dislocation could easily occur.

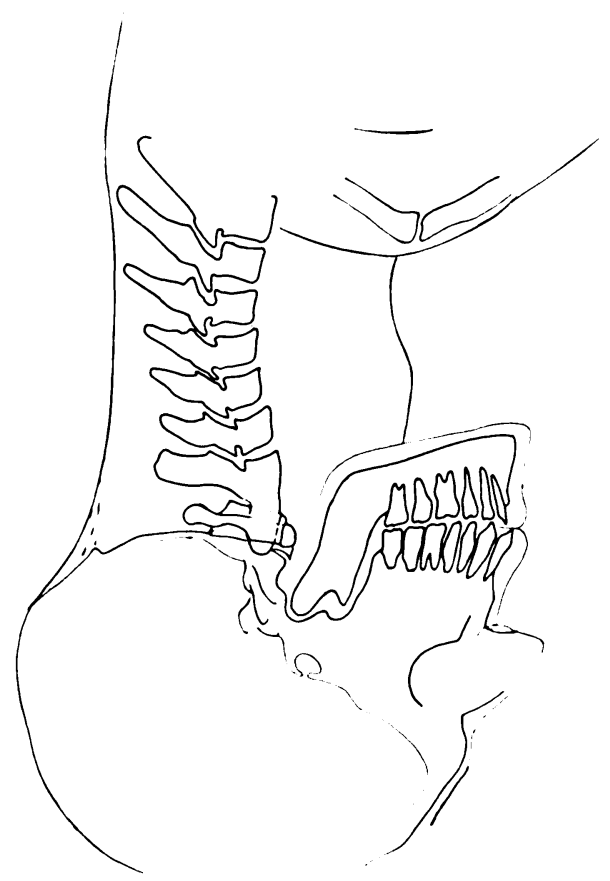

Fig. 17

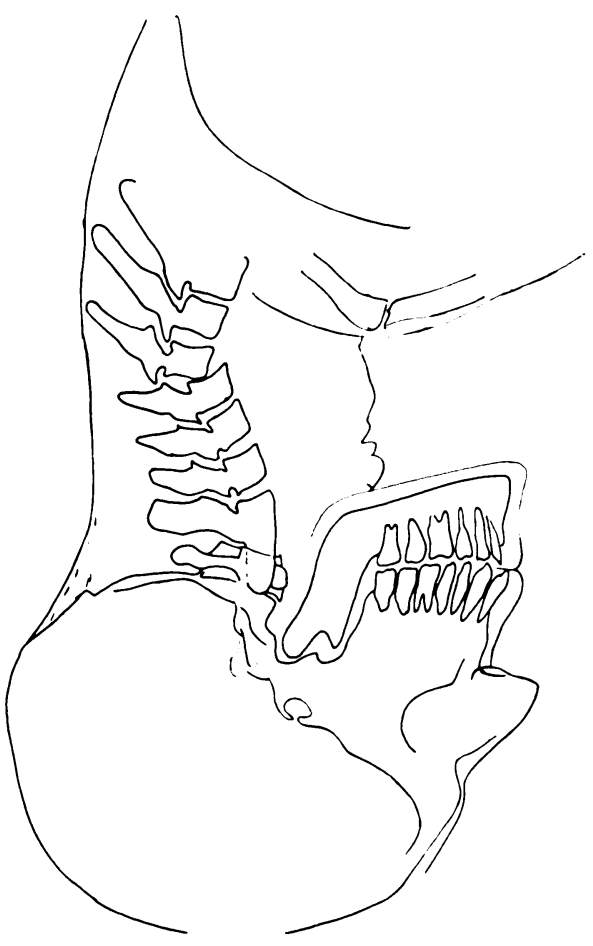

Fig. 18

Figure 17-A diver coming from the right and landing on his head with head and neck in the "ducking" position. Figure 18-Dislocation has occurred by increasing cervical flexion and movement of the body in the expected direction. Note the very small distance that has to be travelled by the dislocating facets.

It is suggested that if a person lands on his head with the whole neck in extension, fractured spinous processes with ruptured anterior longitudinal ligament or anterior avulsion fracture might be expected. If the whole neck is in flexion, then crush fractures are likely to occur, possibly with a fractured sternum or mandible. Figures 17 and 18 show how a diver landing with head and neck in the "ducking" position could easily sustain a dislocation. If rotation and lateral flexion are added to the combined forces and attitude described, unilateral dislocation might be expected.
The maximum vertical load of 145 kilograms was much less than those recorded by Selecki (1970). This is no doubt due to the attitude and movement of the spine in this experiment. Such a load might be expected in dislocation where associated injuries are usually light, and the reader is referred to the typical case shown in Figure 1.

This experiment demonstrates that vertical compression when applied through a lever comprising the head and upper cervical spine is a significant factor in forward dislocation and need not produce any fracture. 
A force applied to an entire cervical spine with atlanto-occipital joints, which is allowed to move in certain directions and which starts off in a particular attitude, produces something quite different to that of the engineering experiment on isolated units with rigidly controlled directional force. The occurrence of the maximum vertical load synchronously with the rupture of the posterior ligaments (interspinous and capsular) and stripping of the anterior longitudinal ligament seems significant. Dislocation occurred after that point, at a lower load. Related to the clinical situation it may be that the conditions for dislocation, as in the experiment, may occur without dislocation, and dislocation be caused subsequently by injudicious handling of the patient.

We are grateful to Mr J. Grant, technician of the Research Laboratory Rehabilitation Unit in Oxford, and to Miss P. Fursdon and the late Miss E. Emrys-Roberts, radiographers of the Nuffield Institute for Medical Research, for their help and suggestions. We also thank Professor R. B. Duthie of the Nuffield Department of Orthopaedic Surgery and Dr P. J. Nicholls of Mary Marlborough Lodge, Oxford, for introducing us to the right people and materials. The difficult photographic work was accomplished by Mr R. Emmanuel of the Nuffield Orthopaedic Centre and Mr J. Smith of the Royal Adelaide Hospital. This work was largely done during the tenure of a Girdlestone Scholarship provided by the Nuffield Orthopaedic Centre Trust.

\section{REFERENCES}

Beatson, T. R. (1963) Fractures and dislocations of the cervical spine. Journal of Bone and Joint Surgery, 45-B, $21-35$.

Braakman, R., and Vinken, P. J. (1967) Unilateral facet interlocking in the lower cervical spine. Journal of Bone and Joint Surgery, 49-B, 249-257.

Cornish, B. L. (1968) Traumatic spondylolisthesis of the axis. Journal of Bone and Joint Surgery, 50-B, 31-43.

Fielding, J. W. (1957) Cineroentgenography of the normal cervical spine. Journal of Bone and Joint Surgery, 39-A, $1280-1288$.

Lysell, E. (1972) The Pattern of Motion in the Cervical Spine, p. 54. Proceedings of a Symposium on Cervical Pain 1971, edited by C. Hirsch and Y. Zotterman. Oxford: Pergamon Press.

Norton, J. L. (1962) Fractures and dislocations of the cervical spine. Journal of Bone and Joint Surgery, 44-A, 115-139.

Roaf, R. (1960) A study of the mechanics of spinal injuries. Journal of Bone and Joint Surgery, 42-B, 810-823.

Selecki, B. R. (1970) Injuries to the Cervical Spine and Cord in Man, p. 17. Australian Medical Association Medical Monograph No. 7.

Taylor, A. R., and Blackwood, W. (1948) Paraplegia in hyperextension cervical injuries with normal radiographic appearances. Journal of Bone and Joint Surgery, 30-B, 245-248. 